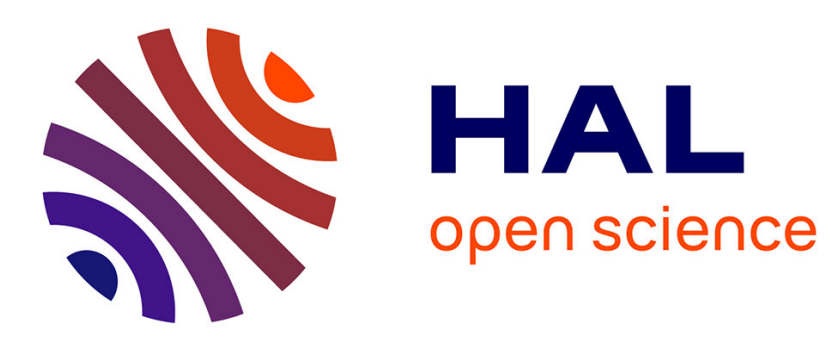

\title{
A simple heat and moisture transfer model to predict ground temperature for shallow ground heat exchangers
}

Maha Chalhoub, Michel Bernier, Yves Coquet, Mikael Philippe

\section{To cite this version:}

Maha Chalhoub, Michel Bernier, Yves Coquet, Mikael Philippe. A simple heat and moisture transfer model to predict ground temperature for shallow ground heat exchangers. Renewable Energy, 2017, 103, pp.295 - 307. 10.1016/j.renene.2016.11.027 . insu-01405482

\section{HAL Id: insu-01405482 \\ https://hal-insu.archives-ouvertes.fr/insu-01405482}

Submitted on 6 Dec 2016

HAL is a multi-disciplinary open access archive for the deposit and dissemination of scientific research documents, whether they are published or not. The documents may come from teaching and research institutions in France or abroad, or from public or private research centers.
L'archive ouverte pluridisciplinaire HAL, est destinée au dépôt et à la diffusion de documents scientifiques de niveau recherche, publiés ou non, émanant des établissements d'enseignement et de recherche français ou étrangers, des laboratoires publics ou privés. 


\section{A simple heat and moisture transfer model to predict ground temperature for shallow ground heat exchangers}

Maha Chalhoub, Michel Bernier, Yves Coquet, Mikael Philippe

Highlights

- Ground source heat exchangers need better models to account for surface effects.

- Simple heat transfer model in the ground using accessible weather data is proposed.

- Soil temperature is well predicted for the first $1.5 \mathrm{~m}$ below the ground surface.

- Surface cover and site-specific conditions are necessary to predict soil temperature.

\section{Abstract}

A simple model is proposed to describe transient heat and moisture transfer in the soil under moderate climates to predict near surface ground temperatures using a minimum set of variables and easily accessible weather data. The model is computationally efficient enough to allow for multi-year simulations of shallow ground heat exchangers. It uses a realistic representation of the interactions between the main processes occurring at the soil surface and the heat and moisture dynamics in the soil including the influence of water content on soil thermal properties. The model has been tested against soil temperature measurements taken at different depths (from 0.06 to $1.5 \mathrm{~m}$ ) on a grass-covered site. Measurements, including meteorological data, were recorded with a time step of $10 \mathrm{~min}$ for one year. It is shown that the agreement between soil temperatures predicted by the proposed model and measurements is relatively good for either dry or rainy conditions. Average errors are between +0.47 and $+1.63{ }^{\circ} \mathrm{C}$. Furthermore, this study shows that a proper account of the soil surface cover and site-specific soil properties is necessary to obtain accurate soil temperature predictions.

Keywords : Heat transfer; Shallow ground heat exchanger; Energy balance; Soil temperature 


\section{Introduction}

Several configurations for near ground surface geothermal heat exchangers have been proposed to avoid the relatively high drilling costs associated with vertical ground heat exchangers (GHE). Horizontal ground heat exchangers [1] and [2] and spiral coil heat exchangers either used directly in the ground or in pile heat exchangers [3], [4] and [5] are two of the most popular configurations. However, these types of exchangers are more sensitive to atmospheric fluctuations and to soil moisture dynamics because they are buried at shallow depths. Naylor et al. [6] and Wu et al. [7] evaluated how site-specific soil properties impact horizontal ground source heat pump (GSHP) systems designed for residential-scale installations. They calculated GHE loop lengths following the International Ground Source Heat Pump Association recommended practice and by using a standard method for estimating soil thermal properties based on simple soil classification obtained from published soil maps. Soil thermal properties were estimated from soil texture, bulk density and seasonal fluctuations in soil moisture. Results showed that GHE design lengths were $44-52 \%$ longer when calculated with the standard generic method. Their results demonstrated the importance of accounting for seasonal climatic variability in design calculations when soils thermal properties show significant seasonal fluctuations. Chong et al. [8] reported on the effect of soil texture and moisture content on the thermal performance of a slinky-loop heat exchanger. The predicted heat extraction rate after 60 days of operation was found to be $37 \mathrm{~W} / \mathrm{m}$ and $6 \mathrm{~W} / \mathrm{m}$ for soils with thermal conductivities of 2.6 and $0.35 \mathrm{~W} /(\mathrm{mK})$, respectively. Casasso and Sethi [9] showed that soil thermal conductivity represents a major source of uncertainty when modeling the operation of GSHPs. They showed a difference of $5.66 \mathrm{~K}$ in the fluid temperature, and $12.5 \%$ in heat pump energy consumption for soil thermal conductivities of 1.0 and $2.5 \mathrm{~W} /(\mathrm{mK})$. Cauret and Bernier [10] reported on the use of $2 \mathrm{~m}$-long compact collectors connected in series and installed in trenches $1 \mathrm{~m}$ below the surface. The agreement between their model and the experiments was satisfactory when taking into account real-time ground temperature measurements.

Even though soil temperature changes spatially and temporally in response to a multitude of factors, GHE designers address soil 


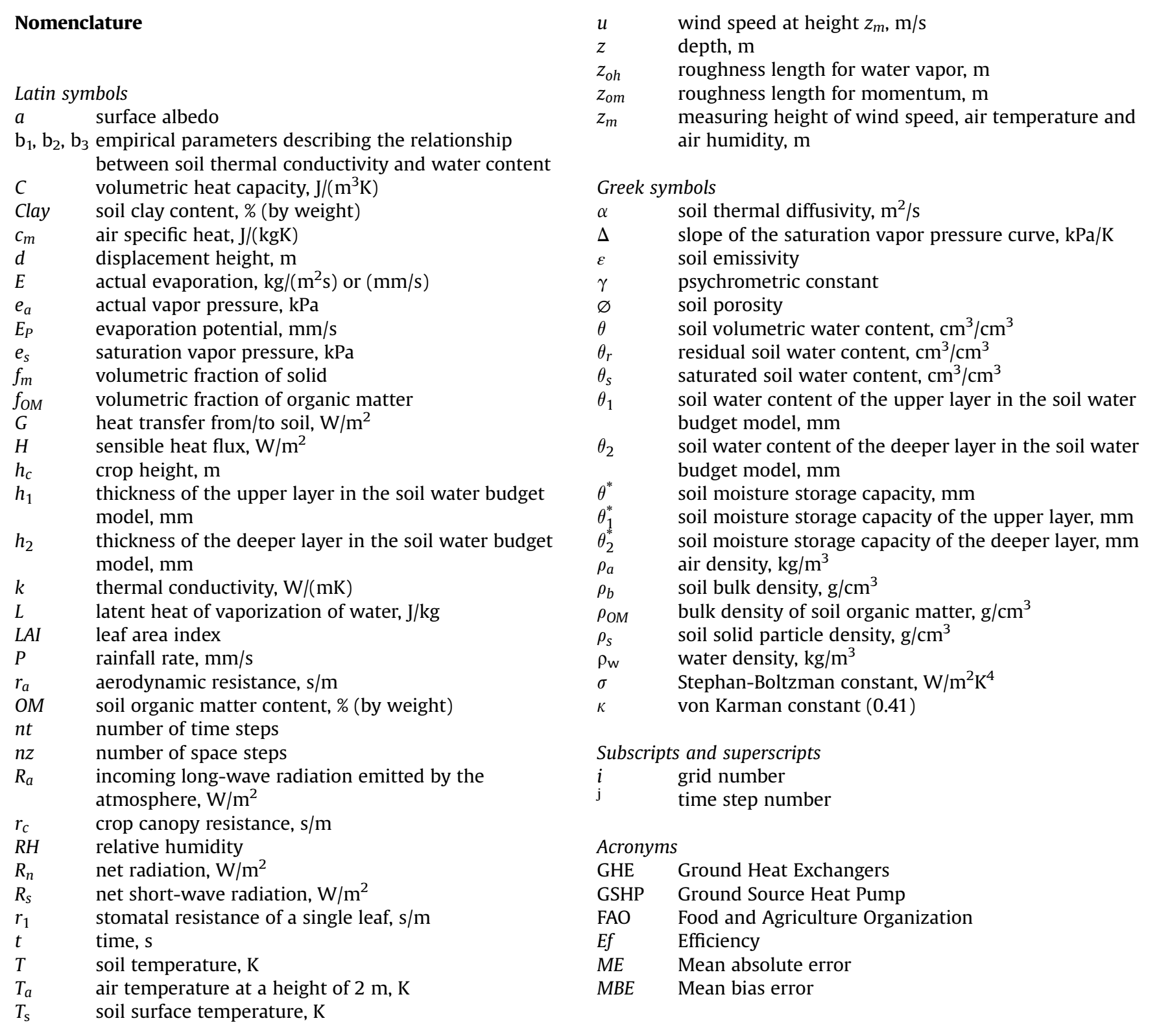

temperature variations with time and depth by relying on simplifying assumptions when incorporating it into complex wholebuilding energy-analysis models. Most often the Kusuda and Achenbach [11] relationship is used. It assumes that soil temperature can be represented by a harmonic function in a homogeneous semi-infinite medium with constant thermal properties. Skhan et al. [12] and Moch et al. [13] developed an analytical solution for a spiral coil type ground heat exchanger by assuming a constant temperature at the surface. Philippe et al. [1] developed an analytical model of a serpentine horizontal ground heat exchanger buried $1 \mathrm{~m}$ below the ground surface assuming constant soil thermal properties. By considering constant surface temperature taken equal to the initial measured soil temperature $\left(7.5^{\circ} \mathrm{C}\right)$, they obtained good agreement with experimental results. However, their results were obtained for a short period $(200 \mathrm{~h})$ during which the soil condition did not vary significantly. Bertermann et al. [14] analyzed very shallow geothermal energy potentials for Europe based on the annual mean air temperature and constant thermal properties derived from relatively simplified data sets. Finally, as noted by Spitler and Bernier [15], most models of GHEs rely on extreme simplifications of the surface boundary conditions and they identified the study of near-surface effects as one of the future research needs on GSHP systems.

In the current work, a simple near surface soil temperature model integrating the transient effects of the soil thermal regime, rainfall events and atmospheric variations is developed. The objective is to accurately predict soil temperature changes with time in the surrounding of shallow ground heat exchangers by utilizing a minimum set of variables and easily accessible weather data. The proposed model is computationally efficient to allow multi-year simulations with hourly data. In order to test the model, a field experiment was carried out over a year with a 10 min time step with measurements of all the components needed to evaluate energy and moisture balances. 


\section{Proposed model}

As shown in Fig. 1, the proposed model involves a two-step process. First, a water budget model predicts the actual evaporation $(E)$ and soil volumetric water content $(\theta)$. Soil moisture variation at a given time-scale is simulated by assuming a two-layer soil composed of two reservoirs in cascade intermittently filled by rainfall events. In a second step, soil temperature is obtained numerically with a realistic soil-atmosphere boundary condition which accounts for: (i) net radiation $\left(R_{n}\right)$ resulting from shortwave $\left(R_{S}\right)$ and long wave radiation $\left(R_{a}\right)$ reaching the soil surface, (ii) convective heat transfer between the soil surface layer and the atmosphere $(H)$, (iii) latent heat due to evapotranspiration $(L E)$, and (iv) heat transfer from and to the ground $(G)$. Temporal variations of soil thermal properties are then related to soil moisture changes. The model is developed for a vegetated surface but can be applied to any other soil surface cover. The modifications to be made to account for other soil surface covers are shown in Appendix A.

\subsection{Soil surface energy balance}

The energy balance at the soil surface is given by:

$R_{n}+H+L E+G=0$

The net radiation, $R_{n}$, is the difference between total incoming and outgoing radiation:

$R_{n}=(1-a) R_{S}+\left(R_{a}-\varepsilon \sigma T_{S}^{4}\right)$ where $(1-a) R_{S}$ is the net short-wave radiation, $a$ is the surface albedo; $R_{a}$ is the incoming long-wave radiation at the soil surface emitted by the atmosphere; $\varepsilon \sigma T_{s}^{4}$ is the long-wave radiation emitted by the ground surface, with $\varepsilon$ the soil emissivity and $\sigma$ the Stephan-Boltzman constant, and $T_{S}$ the soil surface temperature.

The sensible heat flux, $H$, is governed by the difference between the soil surface temperature and the temperature of the atmosphere above:

$H=\rho_{a} c_{m} \frac{\left(T_{s}-T_{a}\right)}{r_{a}}$

where $\rho_{a}$ is the air density; $c_{m}$ is the air specific heat; $T_{a}$ is the air temperature; $r_{a}$ is the aerodynamic resistance to heat transfer which, according to Allen [16], is given by:

$r_{a}=\frac{\ln \left(\frac{z_{m}-d}{z_{o m}}\right) \cdot \ln \left(\frac{z_{m}-d}{z_{o h}}\right)}{k^{2} u}$

With reference to Fig. 2, the vegetation shifts the horizontal asymptote upwards over a displacement height, $d$, the hypothetical soil surface where wind speed is zero. $z_{m}$ is the height above ground level where wind speed, air temperature and air humidity are measured and equals $2 \mathrm{~m}$ (the standard measuring height), $k$ is the von Karman constant (0.41), and $u$ is the wind speed at height $z_{m}$

$d=\frac{2}{3} h_{c}$, with $h_{c}$ the vegetation height

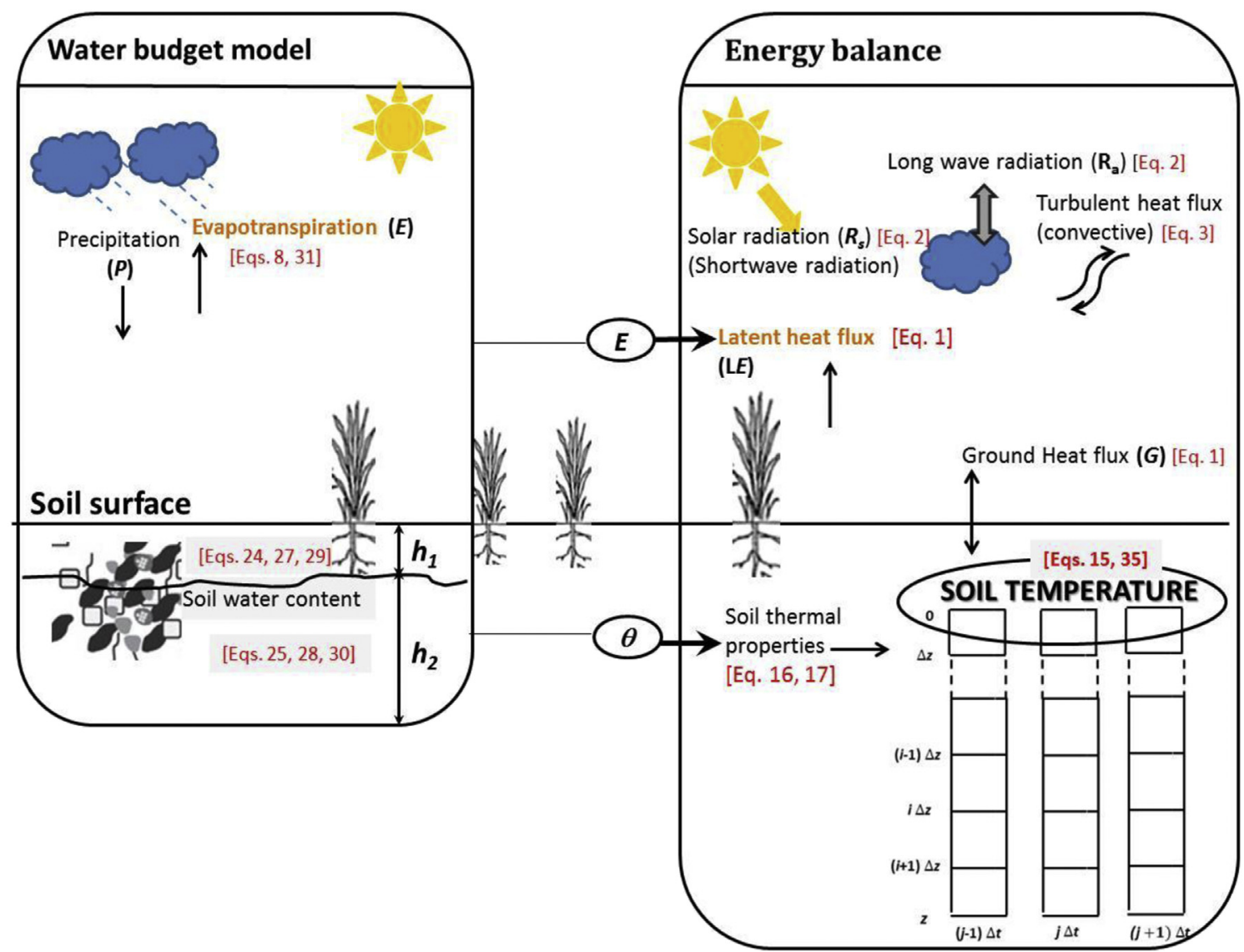

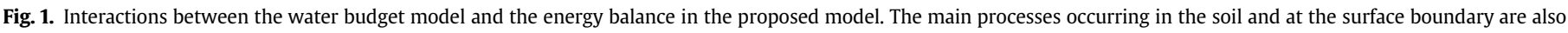
shown. 

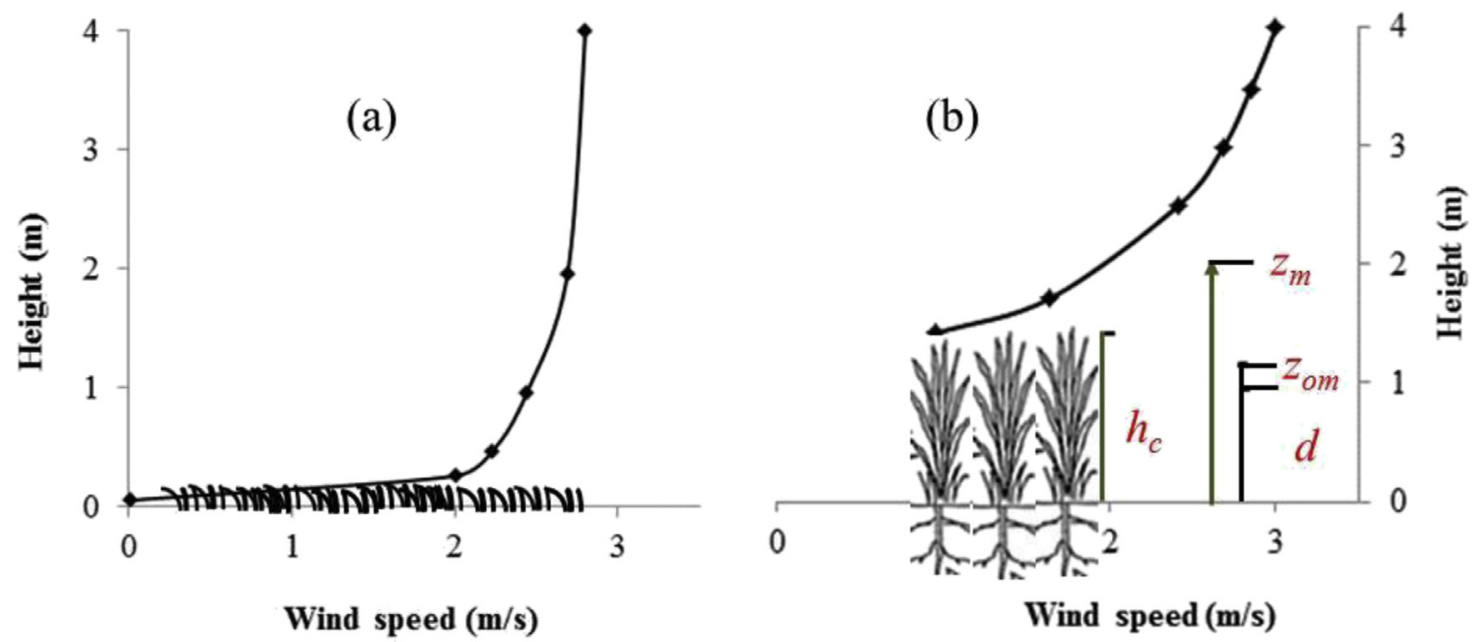

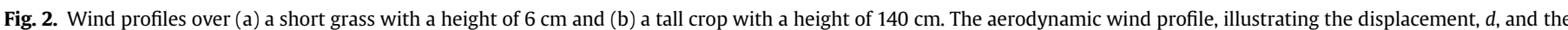
roughness length, $z_{o m}$, are based on the work of Monteith and Unsworth [17]. by:

$z_{o m}$ is the roughness length for momentum transfer calculated

$z_{o m}=0.123 h_{c}$

$z_{o h}$ is the roughness length for vapor transfer taken as:

$z_{o h}=0.1 z_{o m}$

The degree of turbulent mixing that will occur depends on the roughness of the canopy surface. Therefore, a tall crop has a lower aerodynamic resistance value than a smooth grass.

The latent heat flux, $L E$, includes two terms: $L$ is the latent heat of vaporization of water while $E\left(\mathrm{~kg} /\left(\mathrm{m}^{2} \mathrm{~s}\right)\right)$ is the water flux density at the soil surface. It may also be expressed as a volumetric flux density in units of $\mathrm{mm} / \mathrm{s}$, assuming a density of $1000 \mathrm{~kg} / \mathrm{m}^{3}$ for water $\left(\rho_{w}\right)$. The value of $E$ is evaluated by first calculating the evaporation potential, $E_{P}$. This occurs at the soil surface if the water supply from the soil is unrestricted. It is computed using the FAO recommended Penman-Monteith equation [17,18]:

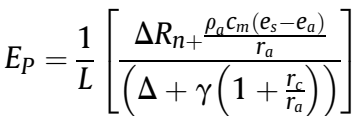

where $\gamma$ is the psychrometric constant; $\left(e_{s}-e_{a}\right)$ is the water vapor pressure deficit, with $e_{s}$ the saturation vapor pressure, and $e_{a}$ the actual vapor pressure. $\Delta$ is the slope of the saturation vapor pressure curve which can be calculated by:

$\Delta=\frac{4098 e_{s}}{\left(T_{a}-35.85\right)^{2}}$

The saturation vapor pressure is related to $T_{a}$ by:

$e_{s}=0.6108 \exp \left(\frac{17.27\left(T_{a}-273.15\right)}{T_{a}-35.85}\right)$

The actual vapor pressure is determined from:

$e_{a}=\frac{R H}{100} \times e_{s}$, where $R H$ is the relative humidity

$r_{c}$ is the crop canopy resistance: $r_{c}=\frac{r_{1}}{0.5 L A I}$

$r_{1}$ is the stomatal resistance of a single leaf $(\sim 100 \mathrm{~s} / \mathrm{m})$; $L A I$ is the leaf area index which, according to Allen et al. [19], is given by:

(a) For clipped grass $\left(h_{c}=0.05-0.15 \mathrm{~m}\right)$ :

$L A I=24 h_{C}$

(b) For other field crops

$L A I=5.5+1.5 \ln \left(h_{c}\right)$

The actual evaporation $E$, governed by the evaporation potential $\left(E_{P}\right)$ and soil water content, is derived from a soil water budget model which is discussed below. When the soil is wet like during rainfall events, $E$ will equal $E_{P}$, otherwise, when the soil is dry it will be less (see 2.3 below).

\subsection{Soil temperature}

One dimensional heat transfer in soil is determined using Fourier's law and conservation of heat:

$C\left(\frac{\partial T}{\partial t}\right)=-k\left(\frac{\partial^{2} T}{\partial z^{2}}\right)$

where $C$ is the soil volumetric heat capacity, $k$ is the soil thermal conductivity, $t$ is time, and $z$ is depth. The ratio $k / C$ gives the soil thermal diffusivity, $\alpha$.

In this work, soil thermal conductivity is related to soil volumetric water content $\theta\left(\mathrm{m}^{3} / \mathrm{m}^{3}\right)$ according to the following equation [20]:

$k(\theta)=b_{1}+b_{2} \theta+b_{3}(\theta)^{0.5}$

where $b_{1}, b_{2}$ and $b_{3}$ are empirical parameters, and $\theta$ is the soil volumetric water content. The volumetric heat capacity can be related to soil composition and wetness according to de Vries [21]: 
$C=1.92 \times 10^{6} f_{m}+2.51 \times 10^{6} f_{O M}+4.18 \times 10^{6} \theta$

where $f_{m}$ and $f_{O M}$ are the volumetric fractions of solid and organic matter in the soil, respectively. They are estimated from soil bulk density $\left(\rho_{b}\right)$ and soil organic matter content OM (\% of organic matter on a mass basis) as follow:

$f_{m}=\frac{\rho_{b}}{\rho_{s}}$

$\varnothing=1-f_{m}$

$f_{O M}=\frac{O M}{1000} \frac{\rho_{b}}{\rho_{O M}}$

where $\varnothing$ is the soil porosity; $\rho_{s}$ is the soil solid particle density, taken equal to $2.65 \mathrm{~g} / \mathrm{cm}^{3}$ (varies between 2.60 and 2.70 in most mineral soils), and $\rho_{O M}$ is the bulk density of soil organic matter.

\subsection{Soil water balance}

The soil moisture dynamics is described by applying a soil-water budget model. This model considers the soil as a reservoir intermittently filled by rainfall events and depleted through loss of water by evaporation. The water budget within the whole soil system is described by the following equation:

$\theta^{j} \times h=\theta^{j-1} \times h+\left(P^{j-1}-E^{j-1}\right)\left(t^{j}-t^{j-1}\right)$

where $\theta^{j}$ is the volumetric soil water content at the current time $j$, $\mathrm{h}$ is the soil depth, $\theta^{j-1}, P^{j-1}$, and $E^{j-1}$ are, respectively, the soil volumetric water content, rate of rainfall and actual evaporation (in $\mathrm{mm} / \mathrm{s})$ at the previous time step $j-1$, and $\left(t^{j}-t^{j-1}\right)$ is the time step. The soil water budget is expressed in units of $\mathrm{mm}$. Soil water content is expressed in equivalent depth of water ( $\mathrm{mm}$ ) by converting the volumetric soil water content $\left(\mathrm{cm}^{3} / \mathrm{cm}^{3}\right)$ as follow:

$\theta=\frac{\text { volume of water }}{\text { volume of soil }}=\frac{\text { area } \times \text { depth of soil water }}{\text { area } \times h}$

depth of soil water $(\mathrm{mm})=\theta \times h(\mathrm{~mm})$

Considering that soil depth in France ranges from 0 to $3 \mathrm{~m}$ [22], the depth, $h$, of the soil reservoir is assumed to be $2 \mathrm{~m}$ in the model. If the soil is vegetated, the soil profile is split in two layers with thicknesses $h_{1}$ and $h_{2}$. The thickness of the upper layer, $h_{1}$, is determined based on root depth. In the present study, $h_{1}$ was set equal to $30 \mathrm{~cm}$ with a corresponding value for $h_{2}$ of $170 \mathrm{~cm}$. The two layers are considered to have the same soil water properties. The soil moisture storage capacity of each layer, $\theta^{*}$, expressed in units of length, differed because it is related to the soil layer thickness as:

$\theta_{1}^{*}=\left(\theta_{s}-\theta_{r}\right) \times h_{1}$

$\theta_{2}^{*}=\left(\theta_{s}-\theta_{r}\right) \times h_{2}$

where $\theta_{s}$ and $\theta_{r}$ denote the saturated and residual volumetric soil water contents, respectively. The value of $\theta_{s}$ is assumed to be equal to the soil porosity (Eq. (19)). The value of $\theta_{r}$ can be predicted from the PedoTransferFunction (PTF) established by Rawls et al. [23] as:

$\theta_{r}=0.026+0.005 \times$ Clay $+0.0158 \times O M$
Where Clay and OM are the clay and organic matter contents of the soil, respectively. When these values are unavailable, they can be estimated using the data of Rawls et al. [23] who established mean values and standard deviations for $\theta_{s}$ and $\theta_{r}$ for 11 soil texture classes. These values are presented in Appendix B.

Soil water content variation with time (in the 1st layer of a twolayer soil), computed for use in calculation of water flux density $(E)$, is described in the following way:

$\theta_{1}^{j} \times h_{1}=\theta_{1}^{j-1} \times h_{1}+\left(P^{j-1}-E^{j-1}\right)\left(t^{j}-t^{j-1}\right)$

where $\theta_{1}^{j}$ and $\theta_{1}^{j-1}$ are the soil water content in the 1 st layer at the current and previous time step, respectively. When the upper layer reaches its soil moisture storage capacity $\left(\theta_{1}^{*}\right)$, the water surplus due to precipitation $\left(\theta_{1}^{j} \times h_{1}-\theta_{1}^{*}\right)$ is assumed to percolate down into the deeper soil layer $\left(\theta_{2}^{j}\right)$ and,

$\theta_{2}^{j} \times h_{2}=\theta_{2}^{j-1} \times h_{2}+\theta_{1}^{j} \times h_{1}-\theta_{1}^{*}$

where $\theta_{2}^{j}$ and $\theta_{2}^{j-1}$ are the soil water content in the 2 nd layer at the current and previous time step, respectively.

Soil water content is not permitted to drop below its residual value or to exceed its soil moisture storage capacity:

$\theta_{1}^{j} h_{1}= \begin{cases}\theta_{r} h_{1}, & \theta_{1}^{j} h_{1}<\theta_{r} h_{1} \\ \theta_{s} h_{1}, & \theta_{1}^{j} h_{1} \geq \theta_{1}^{*}\end{cases}$

$\theta_{2}^{j} h_{2}= \begin{cases}\theta_{r} h_{2}, & \theta_{2}^{j} h_{2}<\theta_{r} h_{2} \\ \theta_{s} h_{2}, & \theta_{2}^{j} h_{2} \geq \theta_{2}^{*}\end{cases}$

The evaporation $(E)$ is computed from the following relations based on the work of Mintz and Walker [24]. When the soil condition is wet (e.g. during rainfall events) $E$ is equal to the evaporation potential, $E_{P}$, otherwise it is less than $E_{P}$ and depends on soil water content (e.g. when the soil is dry).

$E=P+\beta_{d}\left(E_{P}-P\right)$

$\beta_{d}=1-\exp \left(-\frac{6.68 \theta_{1} h_{1}}{\theta_{1}^{*}}\right)$ when $P<E_{P}$

In the two-layer case, the average soil water content is calculated by taking the weighted average of the water content of the two soil layers to estimate soil thermal properties through time (Eqs. (16) and (17)):

$\theta=\frac{h_{1}}{\left(h_{1}+h_{2}\right)} \times \theta_{1}+\frac{h_{2}}{\left(h_{1}+h_{2}\right)} \times \theta_{2}$

\section{Numerical solution}

The solution algorithm for the model is composed of 3 steps (Fig. 3). In the first step, input variables and parameters are initialized. The second step is the computation phase where the components of the energy balance (Equations (1)-(14)) are calculated by changing the values of the state variables according to their previous values and using input variables (air temperature, wind speed, relative humidity, net short-wave radiation and incoming far infrared radiation). Calculation of $L E$ requires knowledge of soil water availability (Eqs. (31) and (32)). The soil water balance is then calculated and the soil water contents updated (Fig. 3). Soil thermal properties, which depend on soil moisture content, are calculated 


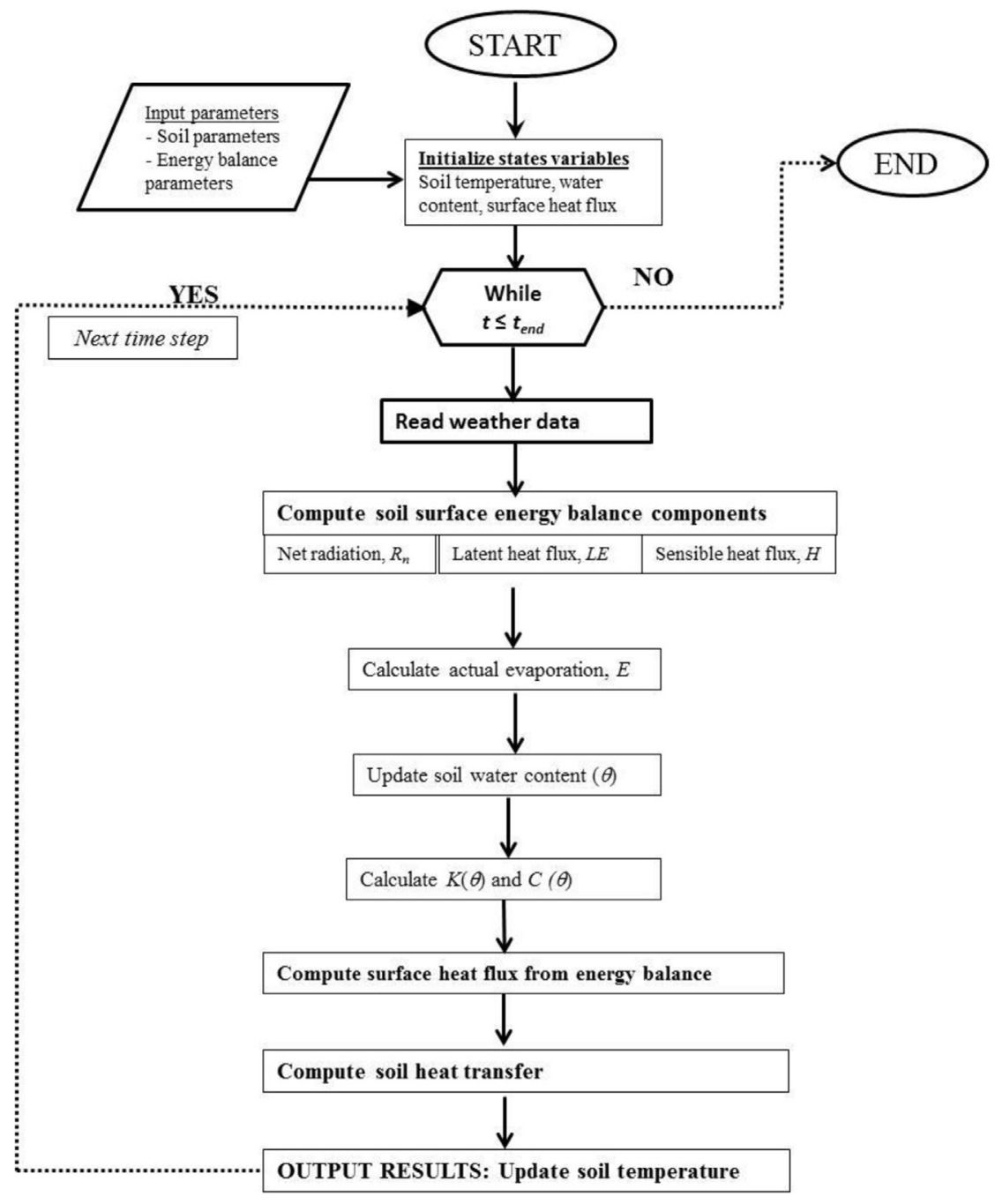

Fig. 3. Flow chart describing the algorithm driving the model.

at each time step from Equations (16)-(17), (33).

At a given time step, $j$, the surface heat flux, $G$, is obtained using the heat fluxes $\left(R_{n}, H\right.$ and $\left.L E\right)$ obtained at the previous time step, $j-1$, as:

$G^{j}=R_{n}^{j-1}-H^{j-1}-L E^{j-1}$

The transient heat equation (Eq. (15)) is solved using an explicit finite difference scheme:

$T_{i}^{j}=T_{i}^{j-1}+\alpha^{j-1} \Delta t\left(\frac{T_{i+1}^{j-1}-2 T_{i}^{j-1}+T_{i-1}^{j-1}}{(\Delta z)^{2}}\right)$

The subscript $i$ refers to the grid number which varies from 1 to $n z$. For the scheme to be stable, the time-evolution is computed at given times with a time step $\Delta t$ which meets the following criteria $\left(\max _{1 \leq j \leq n t}\left(\alpha^{j-1}\right) \frac{\Delta t}{\Delta z^{2}} \leq 1 / 2\right)$.

The surface heat flux $(G)$ is used as a known heat flux boundary condition. $T^{j}$ at the soil surface $(z=0)$ is updated by adding the ground heat flux, computed from the residual of the energy balance according to the following equation:
$T_{1}^{j}=T_{1}^{j-1}+\alpha^{j-1} \Delta t\left(\frac{T_{2}^{j-1}-T_{1}^{j-1}}{(\Delta z)^{2}}\right)+\frac{G^{j-1} \times \Delta t}{C^{j-1} \times \Delta z}$

\section{Experimental validation}

\subsection{Experimental set-up}

An experimental facility equipped with GHEs of various geometries (horizontal, coil-shaped, and vertical boreholes) and located at BRGM in Orleans (France; $1^{\circ} 56^{\prime} 21.13^{\prime \prime} \mathrm{E} ; 4^{\circ} 49^{\prime} 37.2^{\prime \prime} \mathrm{N}$ ) was used to test the model against experimental data obtained over a one year period, from November 2013 to November 2014. The experimental set-up is described in more details in Chalhoub et al. [25] and shown in Fig. 4. The net short-wave radiation and incoming far infrared radiation were measured with an albedometer and a pyrgeometer (DeltaOHM, LP PYRA05, LP PIRG01). At a $2 \mathrm{~m}$ height, the air relative humidity, air temperature and wind speed were measured, respectively, with a capacitive humidity sensor, platinum temperature sensor $\left(100 \Omega @ 0{ }^{\circ} \mathrm{C}\right)$ (Delta-OHM, model HD9008TRR) and an ultrasonic anemometer (Delta-OHM, HD52.3D). Rainfall was measured with a tipping bucket rain gauge 

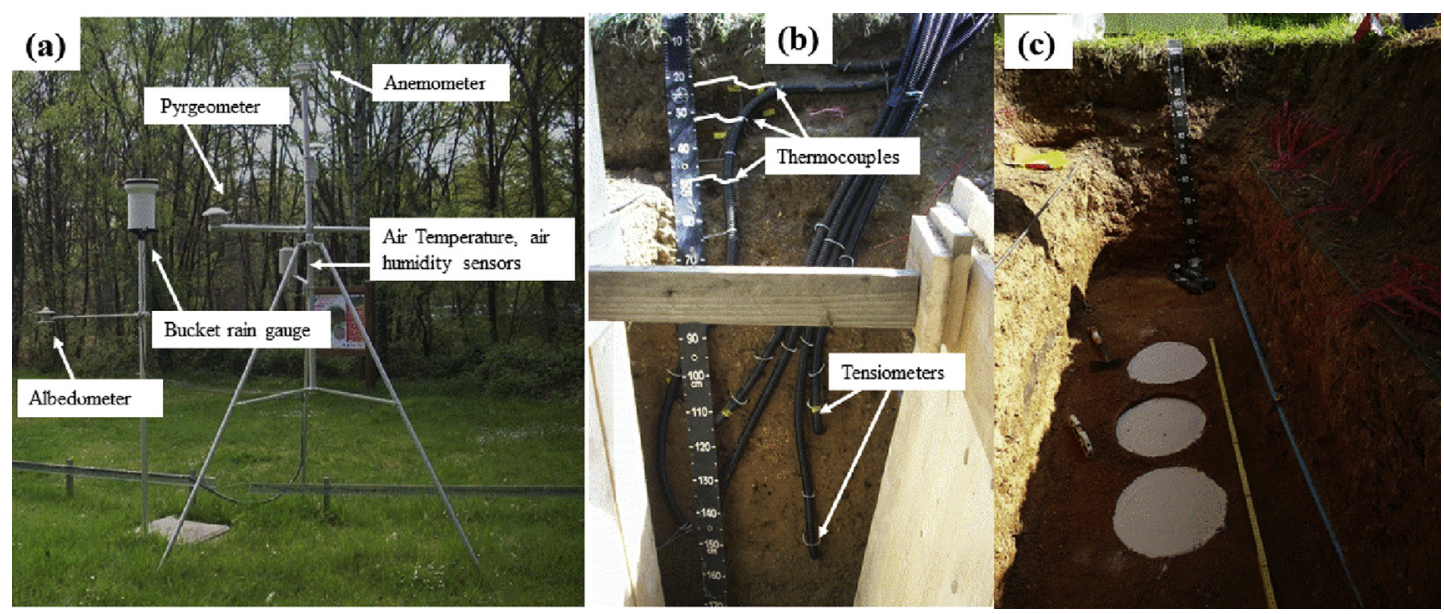

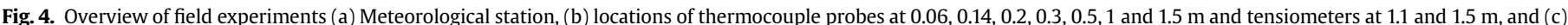
bulk density measurements at $1 \mathrm{~m}$ depth by the sand replacement method.

(Delta-OHM, HD 2013-D). A 2.5 m deep trench has been dug to (i) characterize soil particle size distribution (i.e., clay, sand, organic matter content) and bulk density at $0.15,0.50,1.0$, and $1.5 \mathrm{~m}$ and (ii) install thermocouples and tensiometers allowing continuous measurements of soil temperature and soil matric potential (Fig. 4b). The soil site was instrumented with 10 Type-T thermocouples at depths of $0.06,0.14,0.2,0.3,0.5,1$ and $1.5 \mathrm{~m}$ (two at $0.06 \mathrm{~m}$ and one at each other depth). All measurements were recorded every $10 \mathrm{~min}$. Temporal evolution of the soil water dynamics was recorded three times a day using tensiometers installed at $0.2,0.32,1.1$ and $1.5 \mathrm{~m}$ depths. Average bulk density profiles were measured once by the sand replacement method (AFNOR, 1996 - NF P 94-061-3) using soil cores of $15 \mathrm{~cm}$ by $20 \mathrm{~cm}$ diameter (Fig. 4c). The lawn cover is mowed regularly and fixed at $0.06 \mathrm{~m}$ height.

In order to carry out an analysis of the effect of soil hydraulic and thermal properties on modeling soil temperature variation, soil thermal and hydraulic properties at different depths have been characterized in the laboratory before the start of the experiments. Soil samples were taken right after the trench had been dug (November 2013) at depths of $0.15,0.50,1.0$, and $1.5 \mathrm{~m}$. Three replicates per depth were taken for each measurement. Soil thermal properties were determined by taking undisturbed soil samples ( $10 \mathrm{~cm}$ length by $11 \mathrm{~cm}$ diameter). Soil heat capacity, thermal conductivity and water content were determined using an ISOMET 2114 thermal conductivity instrument (Applied Precision Ltd., Slovakia) and by means of a surface probe at room temperature according to the ASTM D 5334-08/ASTM D 5930-09 methods. Soil water retention properties were measured in the laboratory with a pressure plate apparatus using $50 \mathrm{~cm}^{3}$ soil cores. Water retention parameters were determined by fitting measured retention curves with the van Genuchten (vG) [26] model (Table C1 in Appendix C). The estimated vG parameters and the measured soil pressure head
(Table C2 in Appendix C) were used to estimate soil water content evolution with time.

\subsection{Model parametrization}

A 15 m deep soil profile with zero heat flux at the bottom is used in simulations. This condition assumes that the soil profile is not supplied and affected by upward heat flow from the bottom. The soil profile was discretized uniformly in the vertical direction into 300 nodes to ensure numerical stability. Initial values of soil temperature at the different depths were based on a linear interpolation between the values measured at the site during the first day of test. The initial soil water content was fixed to a value equal to half the porosity measured at the site $\left(0.15 \mathrm{~cm}^{3} / \mathrm{cm}^{3}\right)$. The initial value of surface heat flux $(G)$ was set to zero.

Soil hydraulic and thermal properties were assumed to be constant with depth. The simulations are thus based on one common set of hydraulic and thermal properties for the whole soil profile. Soil bulk density, used to calculate the volume fraction of solid in the soil (Eq. (18)) and soil porosity (Eq. (19)), was taken as the average value of the soil bulk density measurements at different depths $\left(1.89 \mathrm{~g} / \mathrm{cm}^{3}\right.$, Table 1$)$. The volumetric fraction of soil organic matter ( $f_{\mathrm{OM}}$, Eq. $(20)$ ) was calculated from the average soil organic matter content $(O M)$ measured in the field (Table 1$)$. Averaged soil porosity throughout the profile was equal to $29 \%$. Saturated soil water content, $\theta_{s}$, was taken equal to porosity. Residual water content, $\theta_{r}$, was estimated from average values of soil organic matter content and soil clay content (Table 1, Eq. (26)). Other soil thermal properties were taken from the literature. The values of $b_{1}, b_{2}, b_{3}$ (Eq. (16)) were set according to Chung and Horton [20] and were equal to $0.228,-2.406$ and 4.909 , respectively. Parameters related to the energy balance components at the soil surface

Table 1

Main soil physical characteristics (average value of 3 samples \pm standard deviation) as a function of depth.

\begin{tabular}{|c|c|c|c|c|}
\hline & $0.15 \mathrm{~m}$ & $0.5 \mathrm{~m}$ & $1.0 \mathrm{~m}$ & $1.5 \mathrm{~m}$ \\
\hline Clay, g/kgdw ${ }^{\mathrm{a}}$ & $60( \pm 5)$ & $59( \pm 7)$ & $72( \pm 10)$ & $56( \pm 6)$ \\
\hline Silt, g/kgdw & $98( \pm 10)$ & $89( \pm 11)$ & $43( \pm 4)$ & $50( \pm 2)$ \\
\hline Sand, g/kgdw & $468( \pm 21)$ & $421( \pm 21)$ & $560( \pm 73)$ & $508( \pm 27)$ \\
\hline Gravel content, g/kgdw & $374( \pm 15)$ & $430( \pm 25)$ & $325( \pm 69)$ & $386( \pm 27)$ \\
\hline $\mathrm{OM}^{\mathrm{a}}, \mathrm{g} / \mathrm{kgdw}$ & $21( \pm 3)$ & $3( \pm 1)$ & $5( \pm 1)$ & $5( \pm 1)$ \\
\hline Bulk density, $\mathrm{g} / \mathrm{cm}^{3}$ & $1.53( \pm 0.07)$ & $1.90( \pm 0.27)$ & $1.97( \pm 0.07)$ & $2.06( \pm 0.02)$ \\
\hline
\end{tabular}

\footnotetext{
${ }^{a}$ dw: dry weight; OM: organic matter content.
} 
Table 2

Input parameters required for computer simulations.

\begin{tabular}{|c|c|c|c|}
\hline Parameter & Equation & Definition & Value \\
\hline$a$ & Eq. (2) & Albedo (or solar reflectivity) & Measured at the site \\
\hline$\varepsilon(-)$ & Eq. (2) & Soil emissivity & 0.97 \\
\hline$\sigma\left(\mathrm{W} / \mathrm{m}^{2} \mathrm{~K}^{4}\right)$ & Eq. (2) & Stephan-Boltzman constant & $5.67 \times 10^{-8}$ \\
\hline$\rho_{a}\left(\mathrm{~kg} / \mathrm{m}^{3}\right)$ & Eq. (3) & Density of air & 1.25 \\
\hline$c_{m}(\mathrm{~J} / \mathrm{kgK})$ & Eq. (3) & Specific heat of air per unit mass & $1.003 \times 10^{3}$ \\
\hline$\kappa(-)$ & Eq. (4) & von Karman constant & 0.41 \\
\hline$z_{m,} \mathrm{Z}_{\mathrm{h}}(\mathrm{m})$ & Eq. (4) & Height where the meteorological data are collected & 2 \\
\hline$h_{c}(\mathrm{~m})$ & Eqs. (5), (6), (13) and (14) & Crop height & $0.06 \mathrm{~m}$ height \\
\hline$L(\mathrm{~J} / \mathrm{Kg})$ & Eq. (8) & Latent heat of vaporization & $2.45 \times 10^{6}$ \\
\hline$\gamma(\mathrm{kPa} / \mathrm{K})$ & Eq. (8) & Psychrometric constant & 0.063 \\
\hline $\mathrm{r}_{1}(\mathrm{~s} / \mathrm{m})$ & Eq. (12) & Stomatal resistance of a single leaf & 100 \\
\hline $\mathrm{z}_{\mathrm{o}}(\mathrm{m})$ & Eq. (15) & Roughness length & Determined from $h_{c}$ \\
\hline $\mathrm{b}_{1}, \mathrm{~b}_{2}, \mathrm{~b}_{3}(\mathrm{~W} / \mathrm{mK})$ & Eq. (16) & Empirical parameters for Eq. (16) & $0.228,-2.406$ and 4.909 \\
\hline$\rho_{s}\left(\mathrm{~g} / \mathrm{cm}^{3}\right)$ & Eq. (18) & The particle density of mineral soils & 2.65 \\
\hline$\rho_{O M}\left(\mathrm{~g} / \mathrm{cm}^{3}\right)$ & Eq. (20) & The bulk density of soil organic matter & 1.35 \\
\hline$h(\mathrm{~mm})$ & Eqs. (21)-(23) & Thickness of soil & $2 \mathrm{~m}$ \\
\hline$h_{1}(\mathrm{~mm})$ & Eqs. (27), (29), (32) and (33) & Thickness of the 1 st soil layer (vegetated soil) & $0.3 \mathrm{~m}$ (grass root depth) \\
\hline$h_{2}(\mathrm{~mm})$ & Eqs. (25), (28), (30) and (33) & Thickness of the 2 nd soil layer (vegetated soil) & $1.7 \mathrm{~m}$ \\
\hline$\rho_{b}\left(\mathrm{~g} / \mathrm{cm}^{3}\right)$ & Eqs. (18) and (20) & Soil bulk density & Measured at the field \\
\hline Clay, g/kgdw & Eq. (26) & Soil clay content & Measured at the field \\
\hline$O M, \mathrm{~g} / \mathrm{kgdw}$ & Eq. (26) & Soil organic matter content & Measured at the field \\
\hline
\end{tabular}

were obtained from the literature. All the model input values needed are presented in Table 2.

Weather variables required as inputs are precipitation, air temperature, relative air humidity, wind speed and global radiation (short and long wave). All of these were measured with a time resolution of 10 min using an adjacent meteorological station.

The simulation carried out with the model developed here will be referred to as the "reference model". To evaluate the effect of soil hydraulic and thermal properties on modeling soil temperature variation, three other scenarios were examined. The first one, referred to as "Heterogeneous soil", considers two distinct layers with different physical characteristics recorded at the field (Table 1). The topsoil measurements at $0.15 \mathrm{~m}$ depth are characterized by a larger porosity, a larger organic matter content (Table 1) than the deeper soil. Table 3 shows the properties of both layers. The first layer corresponds to the $0-0.3 \mathrm{~m}$ soil layer and had properties attributed from the measurements taken at $0.15 \mathrm{~m}$ depth. The second layer corresponds to soil within the $0.3 \mathrm{~m}$ and $15 \mathrm{~m}$ depth and had the average values of the hydrothermal characteristics observed below $0.3 \mathrm{~m}$ depth (such as soil water storage capacity, bulk density and soil texture). The other two scenarios examined the impact of the transient effects of soil thermal properties on soil temperature prediction. Scenario 1 used variable thermal properties associated with soil water content estimated from soil pressure head recorded in the field. Scenario 2 used constant thermal properties for the whole period which were determined based on averaged experimental value.

\subsection{Metrics to evaluate the proposed model}

Three statistical measures were used to evaluate the ability of

\section{Table 3}

Properties of the homogeneous and heterogeneous soil (two layers-soil with different physico-thermal properties) used to estimate soil temperature variation.

\begin{tabular}{|c|c|c|c|c|}
\hline & $\theta_{\mathrm{s}}$ & $\theta_{\mathrm{r}}$ & $f_{\mathrm{m}}$ & $f_{O M}$ \\
\hline \multicolumn{5}{|c|}{ Soil homogeneous soil (reference model) } \\
\hline$h$ & 0.29 & 0.07 & 0.71 & 0.012 \\
\hline \multicolumn{5}{|c|}{ Soil heterogeneous soil with two distinct layers } \\
\hline$h_{1}$ & 0.42 & 0.09 & 0.55 & 0.024 \\
\hline$h_{2}$ & 0.25 & 0.06 & 0.74 & 0.009 \\
\hline
\end{tabular}

the proposed model to reproduce measured data. The efficiency ( $E f)$ represents the residual variance of the model predictions compared to the variance of the measured data.

$E f=1-\frac{\sum_{j=1}^{n}\left(s_{j}-m_{j}\right)^{2}}{\sum_{j}^{n}\left(m_{j}-\bar{m}\right)^{2}}$

where $m_{j}, s_{j}$ and $\bar{m}$ are the observed values of the variable at time $j$, the simulated values at time $j$ and the mean observed value over the simulated period, respectively. A value of $E f$ close to 1 indicates accurate predictions from the model.

The mean absolute error $(M E)$ is used to check discrepancies between observed and predicted temperature values (the average errors):

$M E=\sum_{j=1}^{n}\left|\frac{s_{j}-m_{j}}{n}\right|$

The mean bias error $(M B E)$ is used to evaluate the bias, that is over- or under-prediction:

$M B E=\sum_{j=1}^{n} \frac{s_{j}-m_{j}}{n}$

\section{Results}

\subsection{Measured soil properties}

The measured soil composition is presented in Table 1. Based on particle size distribution, the soil is sandy. It contains a large proportion of gravels (between 33 and 43\%). Soil thermal properties were measured at different depths (Fig. 5). The thermal conductivity estimated using Eq. (16) and parameters $\left(b_{1}, b_{2}, b_{3}\right)$ proposed by Chung and Horton [20] for sand was within the range of measured data observed at the site (Fig. 5a). However, measured $C$ values (Fig. 5b) were lower than the ones estimated using Eq. (17) proposed by de Vries [21]. Kodešová et al. [27] also observed that soil heat capacity estimated with Eq. (17) differed from measured values. Measurements showed that thermal properties (Fig. 5) at 

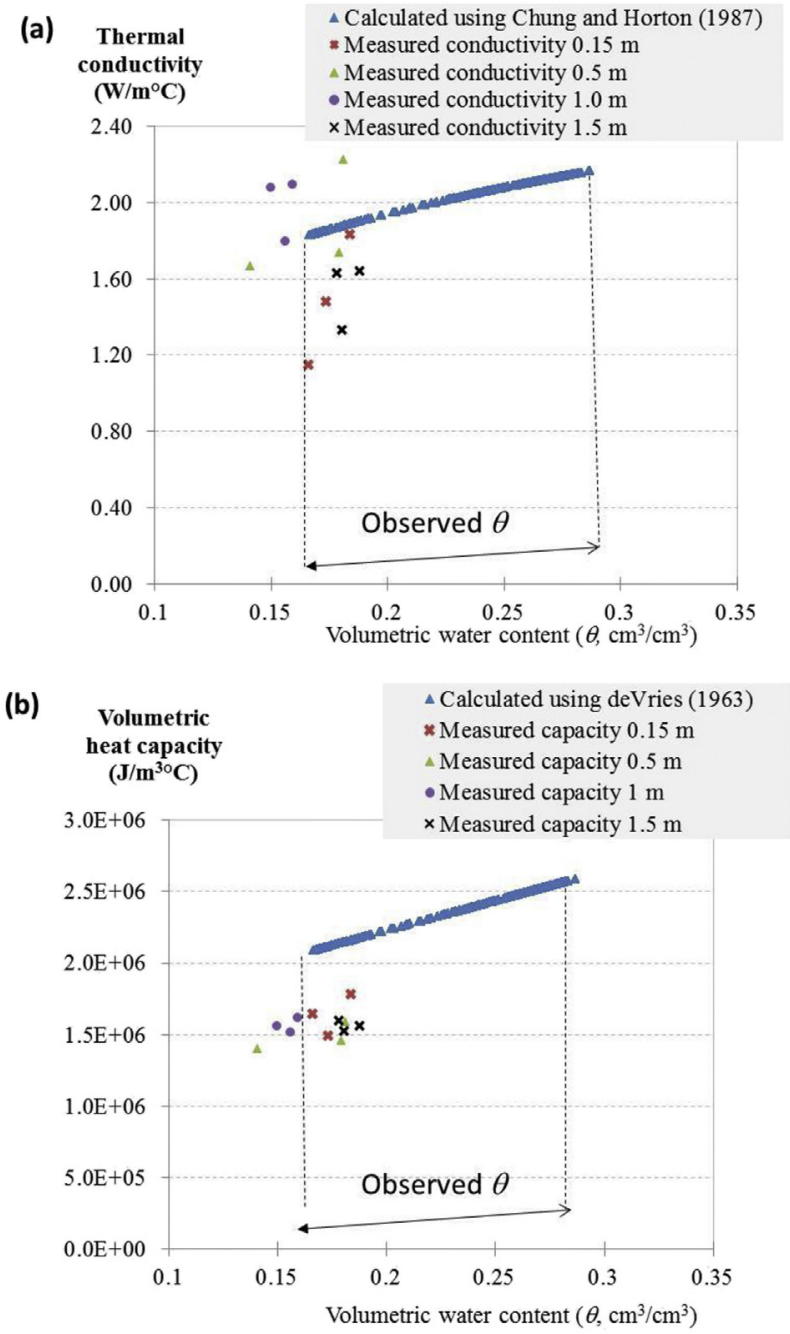

Fig. 5. Evolution of soil thermal conductivity (Eq. (16)) and soil heat capacity (Eq. (17)) using measured water content values recorded during the entire experimental period. Measured soil thermal properties at different depths are also plotted.

each depth were locally variable. Coefficients of variation of local thermal properties calculated from three replicates were between 3 and $23 \%$ for soil thermal conductivity and between 1 and $9 \%$ for soil heat capacity. Variability in local soil thermal properties can be explained by spatial variation of the soil gravel content. The average soil water content varied during the whole experiment between 0.17 and $0.29 \mathrm{~cm}^{3} / \mathrm{cm}^{3}$ which corresponds to degrees of soil saturation of 53 and 83\% (Fig. 5), respectively. Temporal change of soil pressure head was observed to be limited in deep layers (Table C2 in Appendix C). Frequent rainfalls with limited variations of intensity as well as soil compaction (which reduces soil porosity and consequently pore size distribution by reducing large and intermediate-size pores) limited variations of the average soil moisture content during the entire period.

\subsection{Simulation results}

The temporal evolution of soil temperature at different depths recorded on site is presented in Table 4 for the entire year. As shown in this table, near surface soil temperature is the most affected by atmospheric variations. The amplitude of temperature fluctuation at that depth (the difference from maximum to average temperature) is $15{ }^{\circ} \mathrm{C}$. As expected, temperature fluctuations in deeper

\section{Table 4}

The minimum and maximum values of soil temperature recorded on site during the entire experimental period (November 2013-November 2014). Average values are reported in parentheses.

\begin{tabular}{ll}
\hline Depth $(\mathrm{m})$ & Soil temperatures $\left({ }^{\circ} \mathrm{C}\right)$ \\
\hline 0.06 & -0.8 to $27.0(11.6)$ \\
0.14 & -0.1 to $24.7(11.7)$ \\
0.20 & 1.2 to $22.2(11.8)$ \\
0.30 & 1.6 to $21.7(11.8)$ \\
0.50 & 2.5 to $20.9(11.8)$ \\
1 & 4.3 to $19.9(11.9)$ \\
1.5 & 5.9 to $18.4(11.7)$ \\
\hline
\end{tabular}

layers are less pronounced. For example, at depths of 1 and $1.5 \mathrm{~m}$, the amplitudes of temperature fluctuations are 8 and $7{ }^{\circ} \mathrm{C}$, respectively. Simulations were able to reproduce with a good agreement the observed soil temperature at different depths. As shown in Table 5 (reference model), the values for $E_{f}$ are above 0.90 for all depths, except at the $6 \mathrm{~cm}$ depth $\left(E_{f}=0.87\right)$.

Predicted soil temperature at depths of $0.14,0.5,1$ and $1.5 \mathrm{~m}$ are compared to recorded data in Figs. 6 and 7. It is useful to note that only measured values of soil bulk density, clay content and organic matter content and meteorological data were used as inputs to the model. As shown in Figs. 6 and 7, the experimental and simulated soil temperatures show a typical sinusoidal pattern with decreasing amplitude with depth. The overall agreement is reasonably good with average errors $(M E)$ ranging from $0.47^{\circ} \mathrm{C}$ to 1.63 (Table 5). The largest differences are obtained at the soil surface and the lowest at a depth of $1.5 \mathrm{~m}$. At a depth of $0.14 \mathrm{~m}$, the differences range from $-2.44{ }^{\circ} \mathrm{C}$ to $+5.76{ }^{\circ} \mathrm{C}$ while at a depth of $1.5 \mathrm{~m}$ they range from $-0.53{ }^{\circ} \mathrm{C}$ to $+1.66{ }^{\circ} \mathrm{C}$. For the other depths, the ranges of the differences are as follows: $0.5 \mathrm{~m}$ : $-1.41{ }^{\circ} \mathrm{C}$ to $+2.46{ }^{\circ} \mathrm{C}$; $1 \mathrm{~m}:-0.93{ }^{\circ} \mathrm{C}$ to $+1.70{ }^{\circ} \mathrm{C}$. Simulated soil temperatures overestimated the observed values at all depths with $M B E$ ranging from +0.44 to $+1.09{ }^{\circ} \mathrm{C}$ (Table 5 ).

The agreement between measured and simulated data is much better in the second half of the test. The reason for the pronounced overestimation of soil temperature for the first 130 days is unknown, but may be associated with inaccurate estimates of the dynamics of the surface energy components as noted by other researchers. For example, Mahfouf and Noilhan [28] and Saito and Simunek [29] showed that, depending on the methods used to solve the energy balance at the soil-atmosphere interface, simulated soil surface temperatures can easily be altered by $50 \%$ or more. Bittelli et al. [30] reported different results in terms of quantification of the evaporation according to the approaches used to compute the soil surface resistance term (Eq. (4)). For instance, underestimation of the evaporation rate during the period when the soil condition is very wet (the first 130 days) leads to an overestimation of the soil surface temperature. As the choice of the method affects only the calculation of the boundary condition,

Table 5

Model efficiency coefficients ( $E f$ ) for soil temperature at different depths for the simulated period. $M E$ and $M B E$ (for the reference model) are reported in parentheses.

\begin{tabular}{lllll}
\hline Depth $(\mathrm{m})$ & Reference model & Heterogeneous soil & Scenario 1 & Scenario 2 \\
\hline 0.06 & $0.87(1.63 ;+1.09)$ & $0.87(1.68)$ & $0.88(1.59)$ & $0.81(1.94)$ \\
0.14 & $0.93(1.24 ;+1.02)$ & $0.93(1.26)$ & $0.93(1.23)$ & $0.90(1.44)$ \\
0.2 & $0.92(1.27 ;+0.91)$ & $0.92(1.29)$ & $0.92(1.26)$ & $0.89(1.47)$ \\
0.3 & $0.95(1.06 ;+0.85)$ & $0.95(1.05)$ & $0.95(1.05)$ & $0.93(1.21)$ \\
0.5 & $0.97(0.85 ;+0.72)$ & $0.97(0.83)$ & $0.97(0.84)$ & $0.95(0.99)$ \\
1 & $0.98(0.49 ;+0.40)$ & $0.98(0.50)$ & $0.98(0.51)$ & $0.97(0.56)$ \\
1.5 & $0.98(0.47 ;+0.44)$ & $0.98(0.48)$ & $0.98(0.49)$ & $0.97(0.62)$ \\
\hline
\end{tabular}



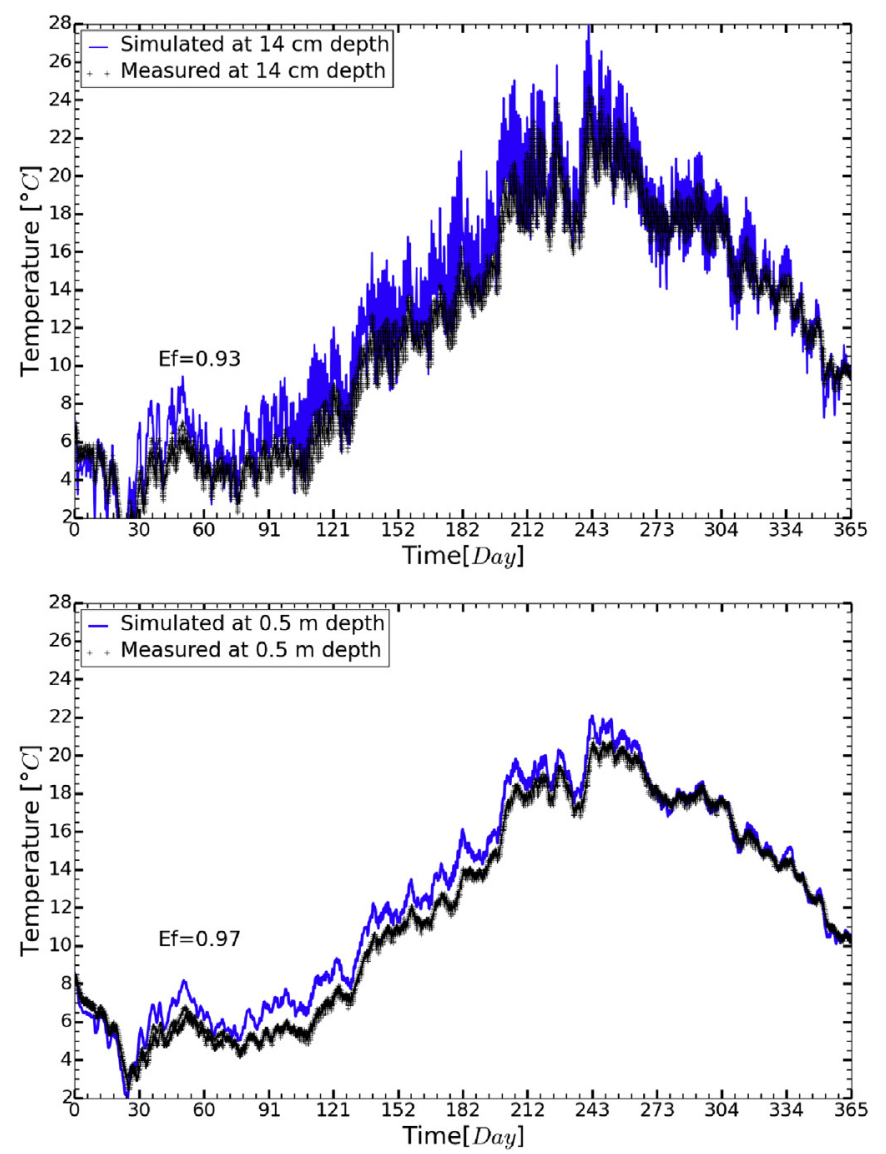

Fig. 6. Simulated (blue lines) and measured values of soil temperature at 0.14 and $0.5 \mathrm{~m}$ depth from November 2013 to November 2014. The efficiency (Ef) is defined in Eq. (37). (For interpretation of the references to colour in this figure legend, the reader is referred to the web version of this article.)

errors induced at the soil surface propagate to deeper layers [29]. At deeper depths, simulated soil temperatures showed a small overestimation compared to the observed values.

Finally, average errors ( $M E)$ obtained here are smaller than those obtained with more physically complicated models, like the coupled liquid water, water vapor, and heat transport model used in the study of Saito and Simunek [29]. They observed mean absolute errors ranging from 2.7 to $1.1^{\circ} \mathrm{C}$ by simulating soil temperatures at depths ranging from 0.15 to $2.0 \mathrm{~m}$. Thus, overall, the proposed model can be used with good accuracy.

\section{Impact of soil thermal and hydraulic properties on the accuracy of the soil temperature predictions}

In the results presented in the previous section, a homogeneous soil has been considered with two layers having similar hydrothermal properties throughout the profile. Simulations were also carried out by considering two distinct layers with different physical characteristics as recorded at the field to check for heterogeneities effects (see Heterogeneous soil scenario in Table 5). Although experimental results indicated some vertical variations of soil hydraulic and thermal properties, soil temperature variations with time and depth were hardly affected by assuming a homogeneous soil. As shown in Table 5, there is a very limited difference in prediction errors between the homogeneous and heterogeneous soil approaches (Table 5). This confirms the findings of Nowamooz et al. [31] who showed that homogeneous and nonhomogeneous soils have similar temperature distributions.
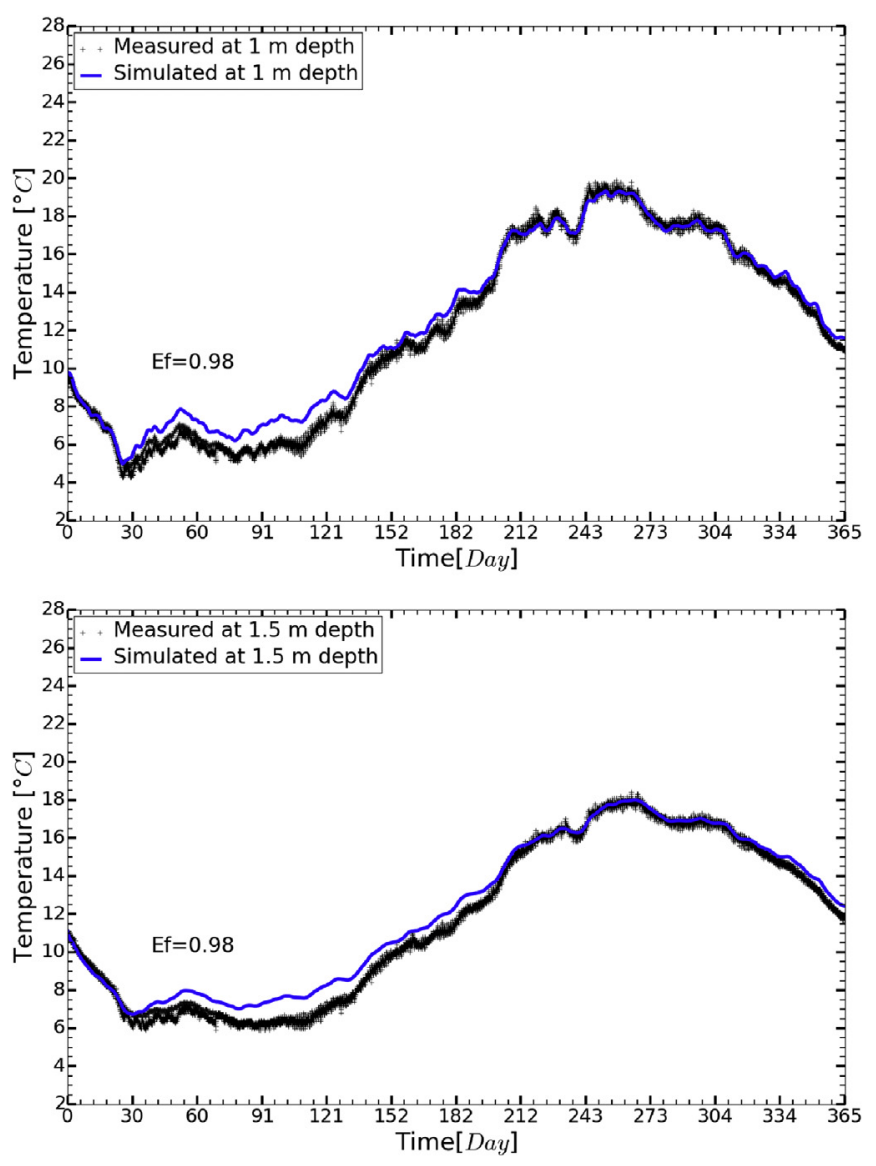

Fig. 7. Simulated (blue lines) and measured values of soil temperature at depths of 1 and $1.5 \mathrm{~m}$. The efficiency $(E f)$ is defined in Eq. (37). (For interpretation of the references to colour in this figure legend, the reader is referred to the web version of this article.)

Two other simulation scenarios (Scenario 1 and 2) were examined to evaluate the effect on soil temperature simulation of simplified methods to estimate soil water content variation with time. Prediction errors of the two scenarios are presented in Table 5 . In scenario 1 , there is a very limited difference with the reference model. This implies that the transient water content effects on soil thermal properties are described correctly by the proposed (reference) model. In Scenario 2, thermal conductivity as well as volumetric heat capacity of the soil profile is set equal to the average of all measurements taken at different depths. Prediction errors are greater at all depths compared to the reference model (Table 4). This shows that considering the effect of water content variation on soil thermal properties is important to correctly simulate temperature variations in soils.

\section{Application to other top boundary conditions and soil texture}

To illustrate the usefulness of the proposed model, numerical simulations were performed assuming (a) a concrete pavement at the soil surface instead of a vegetated surface, (b) high evaporation rates and (c) a clay soil instead of a sandy soil. The aim of this section is to assess the influence of soil surface cover, climatic conditions (e.g. hot climate) and soil texture on soil temperature variations. To simulate asphalt concrete pavement, the albedo (Eq. (2)) was fixed at 0.08 according to Li et al. [32]. Higher evaporation rates were simulated by doubling the rates observed at the field. The hydraulic and thermal properties used to simulate a clay soil are presented in Appendix D. 


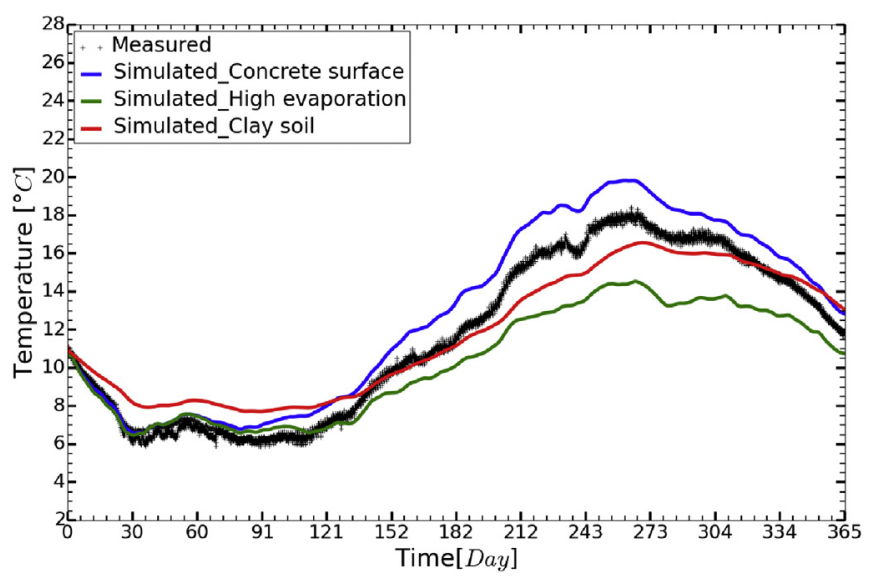

Fig. 8. Comparison of soil temperature at $1 \mathrm{~m}$ depth for (a) a different soil surface cover (asphalt concrete pavement), (b) a different climatic condition (high evaporation) and (c) a different soil texture (clay soil, compared to sandy soil at the site).

Temporal evolution of soil temperature at a depth of $1 \mathrm{~m}$ for these 3 different site-specific conditions is presented in Fig. 8. Soil temperature under the asphalt concrete pavement is significantly higher (about $2{ }^{\circ} \mathrm{C}$ higher than for the vegetated surface) in summer. These findings are consistent with the work of Wu et al. [33] who recorded soil temperature continuously under paved surface and grass within a $3 \mathrm{~m}$ depth during one year. They observed that the average monthly temperatures were $1.8{ }^{\circ} \mathrm{C}$ higher under concrete than under grass. Asphalt pavement (dark color) characterized by low albedo (0.08) can absorb more solar radiation compared to a grass cover (albedo 0.20 ) under the same conditions. In fact, for the results presented in Fig. 8, the mean annual net radiation flux is $51 \mathrm{~W} / \mathrm{m}^{2}$ compared to $43 \mathrm{~W} / \mathrm{m}^{2}$ for the vegetated surface.

Simulation with higher evaporation rates results in lower rate of soil heating by reducing the surface heat flux $(G)$ absorbed by the soil, as shown in Fig. 9. During hot conditions, the main factor in determining soil heat dissipation by evaporation is soil water content. Temporal evolution of soil water content was observed to be small at the experimental site. Under a high atmospheric evaporative demand $\left(E_{p}\right)$, most of the absorbed heat is utilized to evaporize water thus reducing soil temperature. The mean annual soil temperature at a $1 \mathrm{~m}$ depth is reduced from 11.9 to $10.3^{\circ} \mathrm{C}$ for simulations with high rate of evaporation (Fig. 8). The cooling effect is higher in summer with high peak of solar radiation intensity. Results are in accordance with Li et al. [32].

As shown in Appendix D, the soil texture has a significant effect on soil thermal diffusivity. The clay soil has a lower thermal diffusivity than the sandy soil (reference model). Change of soil type from sand (coarse texture and high bulk density) to clay (fine texture and low bulk density) results in a decrease of soil thermal conductivity from 1.98 to $0.7 \mathrm{~W} / \mathrm{mK}$ and a decrease of soil thermal diffusivity by $47 \%$ from 0.87 to $0.40 \mathrm{~mm}^{2} / \mathrm{s}$. Abu-Hamdeh and Reeder [34] showed that sandy soils have higher thermal conductivities than fine-textured soils and that it increases with increasing bulk density as a result of particle contact enhancement as porosity decreases. Reducing soil thermal diffusivity by $47 \%$ reduces the amplitude of soil temperature fluctuation at a $1 \mathrm{~m}$ depth (Fig. 8) from 8 to $6{ }^{\circ} \mathrm{C}$.

\section{Conclusion}

A numerical model that considers soil moisture and heat transfer in the surrounding environment of near surface ground

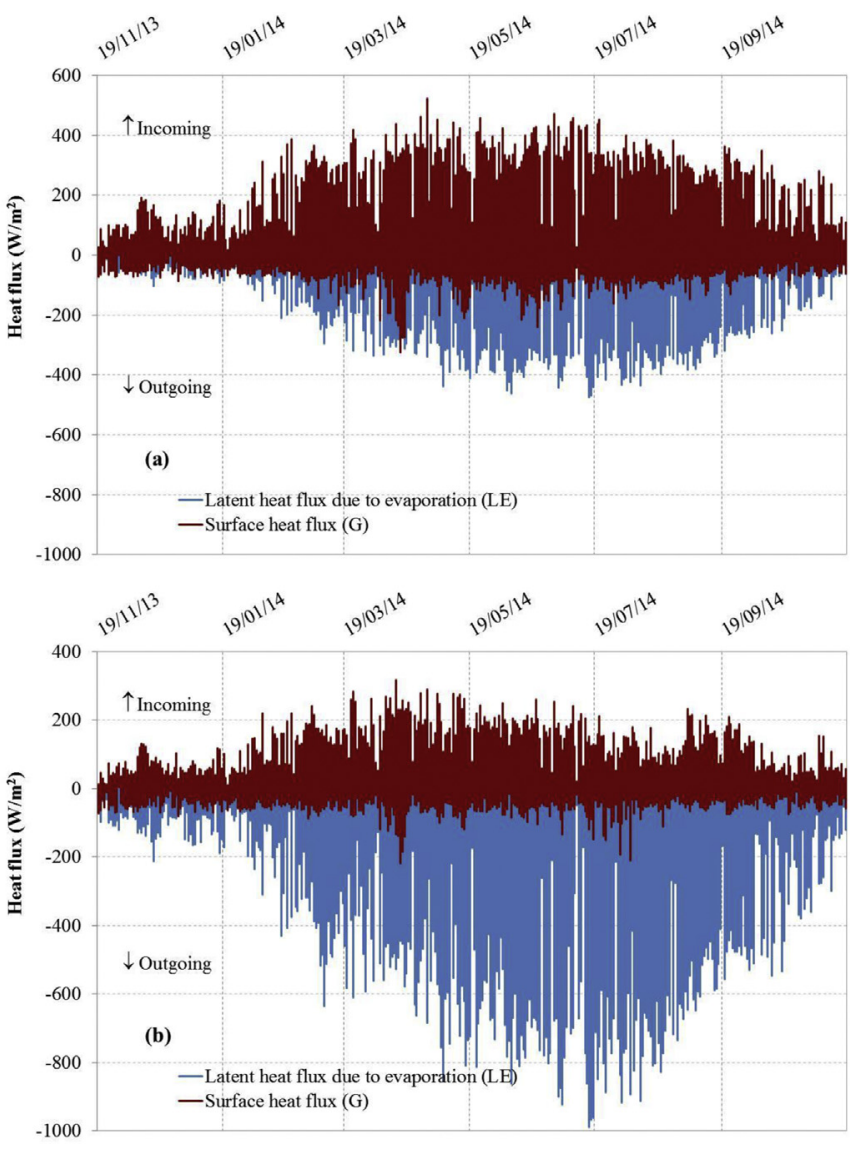

Fig. 9. Impact of climatic-related top boundary condition on surface heat fluxes (a) using climatic data recorded at an adjacent meteorological station, and (b) assuming high rate of evaporation (twice the value in (a)).

heat exchangers has been proposed. The proposed model needs a minimum set of variables and easily accessible weather data. It is computationally efficient to allow multi-year simulations. It predicts soil temperature by coupling water and energy balances at the soil surface with soil moisture and thermal dynamics. Soil heat transfer is solved considering the predominant physical processes at the soil-atmosphere boundary which accounts for net soil surface radiation, turbulent heat transfer between the soil surface layer and the atmosphere, latent heat due to evaporation, and transfer of heat through the soil surface. Temporal variations of soil thermal properties were related to soil moisture changes. Heat and moisture transfer in soil was investigated in situ for a moderate climate to verify the model.

Results show that the model can predict soil temperature with relatively good accuracy; differences in measured and predicted soil temperatures range from 0.47 to $1.63{ }^{\circ} \mathrm{C}$ with the largest differences occurring near the surface.

The model can handle various soil and weather conditions. For example, the vegetated surface used in the reference model was replaced by a concrete asphalt pavement. Simulation results for this condition indicate that the soil temperature is $2{ }^{\circ} \mathrm{C}$ higher at a depth of $1 \mathrm{~m}$ than for the vegetated grass. In another application, a reduction of $47 \%$ of the thermal diffusivity resulted in a decrease of the annual temperature fluctuations at $1 \mathrm{~m}$ depth from 8 to $6{ }^{\circ} \mathrm{C}$.

\section{Acknowledgements}

This work was made possible thanks to a postdoctoral position granted by the CARNOT fund (French National Agency for Research). 


\section{Appendix A}

The following changes are required in Equations (1)-(14) when the surface is not a vegetated surface:

- The albedo is different for a vegetated surface (i.e., 0.23) and a bare surface (0.05-0.50). Albedo and emissivity values for various soil and vegetated surfaces can be found in Evett et al. [35].

- For bare soils, the zero plane displacement $d$ is equal to zero, while typical surface roughness values of $0.003 \mathrm{~m}$ are used for $z_{o}=z_{o m}=z_{o h}$. For asphalt and concrete, roughness length is equal to $0.00002 \mathrm{~m}$. Values of roughness length for various surfaces are proposed in Hansen [36]. Equation (4) is simplified as:

$r_{a}=\frac{\ln \left(\frac{z_{m}}{z_{o}}\right)^{2}}{k^{2} u}$

- The canopy resistance term (Eq. (12)) equals zero so equation (8) simplifies to:

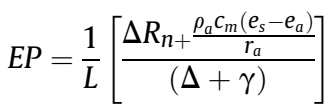

- If the soil is bare, a single uniform soil layer is considered for the soil water budget model $\left(h=h_{1}+h_{2}\right)$.

\section{Appendix B}

The following table gives average values of soil water retention parameters for 11 major soil texture groups according to Rawls et al. [23]. $\theta_{s}\left(\mathrm{~m}^{3} / \mathrm{m}^{3}\right)$ and $\theta_{r}\left(\mathrm{~m}^{3} / \mathrm{m}^{3}\right)$ are the saturated and residual soil water contents, respectively.

\begin{tabular}{lll}
\hline Texture & $\theta_{s}$ & $\theta_{r}$ \\
\hline Sand & 0.417 & 0.020 \\
Loamy sand & 0.401 & 0.035 \\
Sandy loam & 0.412 & 0.041 \\
Loam & 0.434 & 0.027 \\
Silt loam & 0.486 & 0.015 \\
Sandy clay loam & 0.330 & 0.068 \\
Clay loam & 0.390 & 0.075 \\
Silty clay loam & 0.432 & 0.040 \\
Sandy clay & 0.321 & 0.109 \\
Silty clay & 0.423 & 0.056 \\
Clay & 0.385 & 0.090 \\
\hline
\end{tabular}

\section{Appendix C}

\section{Table C.1}

Parameters of the van Genuchten [26] model for the measured soil water retention curves averaged over the different depths.

\begin{tabular}{llll}
\hline$\theta_{r}$ & $\theta_{s}$ & alpha & $n$ \\
\hline$\left(\mathrm{cm}^{3} / \mathrm{cm}^{3}\right)$ & $\left(\mathrm{cm}^{3} / \mathrm{cm}^{3}\right)$ & $(1 / \mathrm{cm})$ & \\
0.00 & 0.31 & 0.07 & 1.19 \\
\hline
\end{tabular}

In this table, $\theta=\theta_{r}+\frac{\theta_{s}-\theta_{r}}{\left[1+|\alpha h|^{n}\right]^{m}}$

where $\theta$ is the soil volumetric water content $\left(\mathrm{cm}^{3} / \mathrm{cm}^{3}\right) ; \theta_{\mathrm{r}}$ is the residual water content $\left(\mathrm{cm}^{3} / \mathrm{cm}^{3}\right) ; \theta_{\mathrm{s}}$ is the saturated water content $\left(\mathrm{cm}^{3} / \mathrm{cm}^{3}\right) ; h$ is soil water potential $(\mathrm{hPa}) ; \alpha$ is a scale parameter inversely proportional to mean pore diameter $(1 / \mathrm{cm}) ; n$ and $m$ are the shape parameters of soil water characteristic, with $m=1-1 / n$.

\section{Table C.2}

The minimum and maximum values of soil pressure head $(h)$ recorded at the field during the whole period of experiment (November 2013-November 2014).

\begin{tabular}{ll}
\hline Depth $(\mathrm{m})$ & Pressure head (mbar) \\
\hline 0.20 & $-659 ;-5$ \\
0.40 & $-648 ;+3$ \\
1.10 & $-24 ;+4$ \\
1.50 & $-14 ;+21$ \\
\hline
\end{tabular}

\section{Appendix D}

The following table shows the hydraulic and thermal input parameters taken from Chung and Horton [20] to simulate a clay soil. $b_{1}, b_{2}, b_{3}$ are empirical parameters describing the relationship between thermal conductivity and soil water content; $\theta_{\mathrm{s}}$ and $\theta_{\mathrm{r}}$ are respectively soil saturated and residual water content; $f_{\mathrm{m}}$ is the volume fraction of soil solid phase. Values in parentheses represent the input used for the sandy soil (reference model)

\begin{tabular}{llllllll}
\hline & $\mathrm{b}_{1}$ & $\mathrm{~b}_{2}$ & $\mathrm{~b}_{3}$ & $\theta_{\mathrm{s}}$ & $\theta_{\mathrm{r}}$ & $f_{\mathrm{m}}$ & $f_{\mathrm{OM}}$ \\
\hline Clay soil & -0.197 & -0.962 & 2.521 & 0.52 & 0.03 & 0.48 & 0.024 \\
& $(0.228)$ & $(-2.406)$ & $(4.909)$ & $(0.29)$ & $(0.07)$ & $(0.71)$ & $(0.012)$ \\
\hline
\end{tabular}

\section{References}

[1] M. Philippe, M. Bernier, D. Marchio, S. Lopez, A semi-analytical model for serpentine horizontal ground heat exchangers, HVAC\&R Res. 17 (6) (2011) 1044-1058.

[2] P.M. Congedo, G. Colangelo, G. Starace, CFD simulations of horizontal ground heat exchangers: a comparison among different configurations, Appl. Therm. Eng. 33-34 (2012) 24-32.

[3] P. Cui, X. Li, Y. Man, Z. Fang, Heat transfer analysis of pile geothermal heat exchangers with spiral coils, Appl. Energy 88 (2011) 4113-4119.

[4] Y. Man, H. Yang, N. Diao, P. Cui, L. Lu, Z. Fang, Development of spiral heat source model for novel pile ground heat exchangers, HVAC\&R Res. 17 (6) (2011) 1075-1088.

[5] S. Park, C. Sung, A. Chauchois, H. Choi, Constructability and heat exchange efficiency of large diameter cast-in-place energy piles with various configurations of heat exchange pipe, Appl. Therm. Eng. 90 (2015) 1061-1071, http:// dx.doi.org/10.1016/j.applthermaleng.2015.05.04.

[6] S. Naylor, K.M. Ellett, A.R. Gustin, Spatiotemporal variability of ground therma properties in glacial sediments and implications for horizontal ground heat exchanger design, Renew. energy 81 (2015) 21-30.

[7] R. Wu, J.M. Tinjum, W.J. Likos, Coupled thermal conductivity dryout curve and soil-water characteristic curve in modeling of shallow horizontal geotherma ground loops, GeotechGeol Eng. 33 (2015) 193-205.

[8] C.S.A. Chong, G. Gan, A. Verhoef, R.G. Garcia, P.L. Vidale, Simulation of thermal performance of horizontal slinky-loop heat exchangers for ground source heat pumps, Appl. Energy 104 (2013) 603-610.

[9] A. Casasso, R. Sethi, Efficiency of closed loop geothermal heat pumps: a sensitivity analysis, Renew. Energy 62 (2014) 737-746.

[10] O. Cauret, M. Bernier, Experimental validation of an underground compact collector model, Effstock 44 (2009) 8. Stockholm, paper.

[11] T. Kusuda, P.R. Achenbach, Earth temperature and thermal diffusivity at selected stations in the United States, ASHRAE Trans. 71 (1) (1965) 61-75.

[12] P. Skhan, L. Seung-Rae, P. Hyunku, Y. Seok, C. Jaywan, Characteristics of an analytical solution for a spiral coil type ground heat exchanger, Comput. 
Geotechnics 49 (2013) 18-24.

[13] X. Moch, M. Palomares, F. Claudon, B. Souyri, B. Stutz, Geothermal helical heat exchangers: comparison and use of two-dimensional axisymmetric models, Appl. Therm. Eng. 73 (2014) 689-696.

[14] D. Bertermann, H. Klug, L. Morper-Busch, A pan-European planning basis for estimating the very shallow geothermal energy potentials, Renew. energy 75 (2015) 335-347.

[15] J. Spitler, M. Bernier, Ground-source heat pump systems: the first century and beyond, HVAC\&R Res. 17 (6) (2011) 891-894, 2011.

[16] R.G. Allen, A Penman for all seasons, J. Irrig. Drain. Eng. 112 (4) (1986) $348-368$

[17] J.L. Monteith, M.H. Unsworth, Principles of Environmental Physics, fourth ed., Edward Arnold, New York, 2013.

[18] T. Davie, Fundamentals of Hydrology, 2d ed., Taylor and Francis group, London and New York, 2008.

[19] R.G. Allen, M.E. Jensen, J.L. Wright, R.D. Burman, Operational estimates of evapotranspiration, Agron. J. 81 (1989) 650-662.

[20] S.O. Chung, R. Horton, Soil heat and water flow with a partial surface mulch, Water Resour. Res. 23 (12) (1987) 2175-2186.

[21] D.A. de Vries, The thermal properties of soils, in: R.W. van Wijk (Ed.), Physics of Plant Environment, North Holland, Amsterdam, 1963, pp. 210-235.

[22] M. Lacoste, V.L. Mulder, N. Saby, D. Arrouays, High-resolution spatial modelling of total soil depth for France, Nanjing, CHN (2014-11-11 -2014-11-14), in: Presented at 6th Global Workshop on Digital Soil Mapping, 2014, http:// prodinra.inra.fr/record/286899.

[23] W.J. Rawls, D.L. Brakensiek, K.E. Saxton, Estimation of soil water properties, Trans. ASAE 25 (5) (1982), 1316-1320 and 1328

[24] Y. Mintz, G.K. Walker, Global fields of soil moisture and land surface evapotranspiration derived from observed precipitation and surface air temperature, J. Appl. meteorology 32 (1993) 1305-1334.

[25] Chalhoub M, Philippe M, Coquet Y. A Field experiment to assess the influence of heat and mass transfer at the soil surface on shallow ground heat exchanger performances. Proceedings World Geothermal Congress 2015,
Melbourne, Australia, 19-25 April 2015.

[26] MTh van Genuchten, A closed-form equation for predicting the hydraulic conductivity of unsaturated soils, Soil Sci. Soc. Am. J. 44 (1980) 892-898.

[27] R. Kodešová, M. Vlasáková, M. Fér, D. Teplá, O. Jakšík, P. Neuberger, R. Adamovský, Thermal properties of representative soils of the Czech Republic, Soil Water Res. 8 (2013) 141-150.

[28] J.F. Mahfouf, J. Noilhan, Comparative study of various formulations of evaporation from bare soil using in situ data, J. Appl. meteorology 30 (1991) 1354-1365.

[29] H. Saito, J. Simunek, Effects of meteorological models on the solution of the surface energy balance and soil temperature variations in bare soils, J. hydrology 373 (3-4) (2009) 545-561.

[30] M. Bittelli, F. Ventura, G.S. Campbell, R.L. Snyder, F. Gallegati, P.R. Pisa, Coupling of heat, water vapor, and liquid water fluxes to compute evaporation in bare soils, J. Hydrology 362 (2008) 191-205.

[31] H. Nowamooz, S. Nikoosokhan, J. Lin, Chazallon. Finite difference modeling of heat distribution in multilayer soils with time-spatial hydrothermal properties, Renew. energy 76 (2015) 7-15.

[32] H. Li, J. Harvey, A. Kendall, Field measurement of albedo for different land cover materials and effects on thermal performance, Build. Environ. 59 (2013) 536-546.

[33] J. Wu, C. Tang, B. Shi, L. Gao, H. Jiang, J.L. Daniels, Effect of ground covers on soil temperature in urban and rural areas, Geol. Soc. Am. 20 (3) (2014) 225-237.

[34] N.H. Abu-Hamdeh, R.C. Reeder, Soil thermal conductivity: effects of density, moisture, salt concentration, and organic matter, Soil Sci. Soc. Am. J. 2000 (64) (2000) 1285-1290.

[35] S.R. Evett, J.H. Prueger, J.A. Tolk, Water and Energy Balances in the soil-plantatmosphere continuum, in: P.M. Huang, Y. Li, M.E. Summer (Eds.), Handbook of Soil Sciences: Properties and Processes, 2d ed, CRC Press, Boca Raton, 2012. pp. 6.1-6.45.

[36] F.V. Hansen, Surface Roughness Lengths, ARL Technical Report, U. S. Army, White Sands Missile Range, NM 88002-5501, 1993. 